\title{
Utility of Magnetic Resonance Imaging in Diagnosis and Monitoring Enthesitis in Patients with Spondyloarthritis: An OMERACT Systematic Literature Review
}

\author{
Ashish J. Mathew (D), Simon Krabbe (D), Richard Kirubakaran (i), Andrew J. Barr(i), \\ Philip G. Conaghan (1), Paul Bird (D), and Mikkel Østergaard (D)
}

\begin{abstract}
Objective. A systematic literature review was performed to document published magnetic resonance imaging (MRI) lesion definitions and scoring systems for enthesitis in spondyloarthritis (SpA).

Methods. PubMed, Embase, and Cochrane Library databases were searched for original publications involving adult patients with SpA undergoing MRI of axial/peripheral joints. Selected articles were assessed for quality using a standardized assessment tool and metric indices.

Results. Considering the heterogeneous design, quality, and outcome measures of studies, statistical data pooling was considered inappropriate. A qualitative narrative of results was undertaken based on study designs.

Conclusion. Lack of a comprehensive, validated score warrants additional research to develop an MRI enthesitis scoring system. PROSPERO registration number: CRD42018090537. (First Release March 1 2019; J Rheumatol 2019;46:1207-14; doi:10.3899/jrheum.181083)
\end{abstract}

Key Indexing Terms:

ENTHESOPATHY

MAGNETIC RESONANCE IMAGING

SPONDYLOARTHROPATHY

INFLAMMATION

OMERACT

From the Department of Clinical Immunology and Rheumatology, Christian Medical College; Cochrane South Asia, Christian Medical College, Vellore, India; Department of Clinical Medicine, Faculty of Health and Medical Sciences, University of Copenhagen; Copenhagen Center for Arthritis Research (COPECARE), Copenhagen; Center for Rheumatology and Spine Diseases, Rigshospitalet Glostrup, Glostrup, Denmark; UK National Institute for Health Research (NIHR) Leeds Biomedical Research Centre (BRC), Leeds Teaching Hospitals National Health Service (NHS) Trust; Leeds Institute of Rheumatic and Musculoskeletal Medicine, University of Leeds, Leeds, UK; Division of Medicine, University of New South Wales, Sydney, Australia.

$A J B$ and PGC are supported in part through the NIHR Leeds BRC. The views expressed in this article are those of the authors and not necessarily those of the NHS, the NIHR, or the UK Department of Health. A.J. Mathew, MBBS, DNB, DM, Associate Professor, Department of Clinical Immunology and Rheumatology, Christian Medical College, and PhD Fellow, Department of Clinical Medicine, Faculty of Health and Medical Sciences, University of Copenhagen, and COPECARE, Center for Rheumatology and Spine Diseases, Rigshospitalet Glostrup; S. Krabbe, $M D$, Department of Clinical Medicine, Faculty of Health and Medical Sciences, University of Copenhagen, and COPECARE, Center for Rheumatology and Spine Diseases, Rigshospitalet Glostrup;

R. Kirubakaran, BSc, MSc, Biostatistician, Cochrane South Asia, Christian Medical College; A.J. Barr, MRCP, PhD, Consultant Rheumatologist and Honorary Senior Lecturer, NIHR Leeds BRC, Leeds Teaching Hospitals NHS Trust; P.G. Conaghan, MBBS, PhD, FRACP, FRCP, Professor of Musculoskeletal Medicine, Leeds Institute of Rheumatic and

Musculoskeletal Medicine, University of Leeds, and NIHR Leeds BRC; P. Bird, B Med (Hons), FRACP, PhD, Grad Dip MRI, Associate Professor, Division of Medicine, University of New South Wales; M. Østergaard, MD, PhD, DMSc, Professor, Department of Clinical Medicine, Faculty of Health and Medical Sciences, University of Copenhagen, and COPECARE, Center for Rheumatology and Spine Diseases, Rigshospitalet Glostrup.

Address correspondence to A.J. Mathew, Department of Clinical

Immunology and Rheumatology, Christian Medical College, Vellore, India, 632004.E-mail: ashishjacobmathew@gmail.com

Accepted for publication January 9, 2019.
Enthesitis, inflammation at the insertion site of tendon, ligament, or joint capsule into bone, is considered a key pathological feature in spondyloarthritis (SpA) and psoriatic arthritis (PsA) ${ }^{1}$. Compared to conventional assessment of enthesitis using clinical scores, magnetic resonance imaging (MRI) detects both soft tissue and intraosseous abnormalities in active enthesitis, potentially aiding early diagnosis and outcome measurement in $\mathrm{SpA}$ and $\mathrm{PsA}^{2}$. With the advent of the treat-to-target concept and novel therapies, objective and sensitive monitoring of response of enthesitis to therapy is desirable, and a validated MRI scoring system would be a useful adjunct to clinical practice as well as providing additional information as an outcome measure in clinical trials.

The Outcome Measures in Rheumatology (OMERACT) MRI in Inflammatory Arthritis Working Group undertook a systematic literature review to describe the MRI variables, definitions, and scoring systems used to diagnose and monitor enthesitis in SpA. We assessed the quality and reported psychometric qualities, including validity, reliability, and responsiveness of original publications, to understand whether there was a need for a novel MRI scoring system for enthesitis in $\mathrm{SpA}^{3,4}$.

\section{MATERIALS AND METHODS}

Selection criteria and search strategies. We searched Medline, Embase, and Cochrane Library databases from their inception until February 2018 for original publications involving adult patients ( $>18 \mathrm{yrs}$ ) with $\mathrm{SpA}$ in whom

Personal non-commercial use only. The Journal of Rheumatology Copyright @ 2019 . All rights reserved. 
MRI of axial or peripheral joints had been performed using a high-field magnet $(\geq 1.5 \mathrm{~T})$ to assess enthesitis. Exclusion criteria included studies on enthesitis related to other conditions, such as degenerative, trauma-related, and inflammatory diseases other than $\mathrm{SpA}$. The search strategy was designed to select cross-sectional, case control, randomized controlled, and nonrandomized studies in the English language containing at least 1 term from each of the following search blocks: (1) spondyloarthritis, spondylarthritis, psoriatic arthritis, or ankylosing spondylitis; (2) enthesopathy, enthesitis or enthesis; and (3) magnetic resonance imaging or MRI. The selected studies were evaluated for definitions of MRI enthesitis lesions, quality of studies using a standardized assessment tool, and for their metric qualities.

Selection of studies and data extraction. Two reviewers (AJM and SK) independently selected the studies and systematically screened the titles and abstracts, applying inclusion and exclusion criteria. Selected articles were retrieved in full, and the same reviewers assessed each article for its eligibility. Disagreements between the reviewers on article selection were resolved by discussion. Data were extracted to a standardized form. Any discordance in opinion was resolved by consensus and involvement of a third reviewer $(\mathrm{M} \varnothing)$. The data extraction sheet contained the following information: author, year of publication, study design, study population, number of participants, intervention, comparator, MRI field strength, sequences used, MRI sites used for evaluating enthesitis, definitions of MRI inflammatory and structural enthesitis, and scoring system used (Table 1).

Quality assessment of selected studies. A standardized tool (Supplementary Table 1, available with the online version of this article) for quality assessment of the analyzed studies based on a set of 12 predefined criteria addressing the following components was developed and assessed in a binary mode (yes/no): study population, enthesitis imaging feature, outcome of interest, study design and analysis, and data presentation. Concepts from review of quality assessment tools in systematic reviews of observational studies were adapted for developing these criteria ${ }^{5}$. Quality was reported on a scale of $0-12$, with higher scores indicating better quality. Included studies that scored $<3$ on the scale were excluded from the final analysis.

Psychometric properties of included studies. Each selected article was analyzed and assessed to determine whether it satisfied certain aspects of validity. The following metric qualities were evaluated: face and content validity, construct validity, criterion validity, and discriminant validity (reliability and responsiveness; Table 2).

Statistical analysis. Details of the studies were reported with descriptive statistics such as frequencies and percentages for categorical data and mean and SD for continuous data. Because of variability in studies, metaanalysis could not be performed. PROSPERO registration number: CRD42018090537.

\section{RESULTS}

Literature search. The study selection process is depicted in a PRISMA (Preferred Reporting Items for Systematic reviews and Meta-Analyses) flow diagram (Figure 1).

Study characteristics. Attributes of the included studies are summarized in Table $1^{2,6-43}$. The majority of included studies were of cross-sectional design $(20 ; 51 \%)^{2,6-17,19-24,28}$. Eight case-control $^{18,25-27,29-32}, 6$ cohort $^{33,34,35,36,37,38}, 3$ randomized controlled trials $\mathrm{s}^{39,40,41}$, and 2 other longitudinal studies $^{42,43}$ were included. Study populations involved SpA in 22, ankylosing spondylitis in 7, and PsA in 9 studies, and chronic low back pain in 1 study. In total, 1534 individuals (range 8-127) in different groups were evaluated for MRI enthesitis in all the studies together. Peripheral enthesitis were evaluated in 24 (62\%) studies $7,10,11,15-29,31,32,34,36,38,39$, axial enthesitis in 8 studies $6,8,12,15,14,36,42,43$, and enthesitis at both sites using whole-body MRI in 7 studies $2,9,30,33,37,40,41$. Both
T1-weighted (T1w) and T2w fat-suppressed or its comparable sequences were included in all the studies. Comparison with other methods of evaluating enthesitis [ultrasonography (US) and clinical assessment] was described in 10 studies $7,9,10,11,18,30,31,32,35,36$, while 5 studies compared different MRI sequences to assess enthesitis ${ }^{6,13,14,25,42}$. Only 4 studies compared efficacy of MRI against a gold standard $11,13,35,42$.

Qualitative assessment of enthesitis at different regions was used in $82 \%$ of studies. Only 8 studies mentioned a semiquantitative or quantitative MRI scoring system $^{2,14,16,17,19,25,39,40}$. No studies described a validated, comprehensive MRI scoring system measuring all the aspects of enthesitis in any region. The majority of studies defined inflammatory enthesitis as enhancement of ligaments, increased signal intensity, perientheseal increased signal intensity, adjacent bone marrow edema (BME), soft tissue signal around ligaments or tendons, thickening of ligaments, capsulitis in sacroiliac joints, extracapsular soft tissue enhancement, Achilles tendon diameter of BME, perientheseal fluid and/or tendinitis in T1w post-gadolinium, or short-tau inversion recovery sequences. Entheseal structural damage defined by few studies includes bone erosions, enthesophytes, focal signal intensity changes, and calcaneal spur in T1w sequences $2,7,16,25,27,28,29,32$.

Quality assessment of included studies. Quality scores assessed using a standardized tool are provided in Table 2. With 1 exception, all 38 studies met the minimal quality requirement score of 4 . High quality scores (10-12) were present in only 2 studies $^{2,40}$, while the remaining 36 studies had moderate quality scores (5-9).

Assessment of psychometric properties. Table 2 describes psychometric properties of the selected studies. Face validity was assessed in $33(87 \%)$ studies, content validity in 19 $(50 \%)$ studies, and construct validity of MRI as related to ultrasound (US) and clinical examination in 5 (13\%) and 6 (16\%) studies, respectively. Five studies reported construct validity of different MRI sequences in relation to each other $6,13,14,25,42$. Criterion validity of MRI in relation to histology was described only by Tan, et $a l^{22}$. Reliability of MRI in detecting enthesitis using various scoring methods was reported by $26(68 \%)$ studies in which images were evaluated by 2 independent readers who were blinded to clinical outcomes. Responsiveness of various MRI enthesitis scores was reported in $6(18 \%)$ studies, of which 3 showed statistically significant changes $(\mathrm{p}<0.05)^{37,40,41}$.

\section{DISCUSSION}

Axial and peripheral enthesitis constitutes a core feature of SpA and PsA. The OMERACT PsA core domain set includes enthesitis, which makes it mandatory to be assessed in all clinical trials and observational studies ${ }^{44}$. MRI allows sensitive assessment of enthesitis in clinical trials. We have critically evaluated the published literature for available

Personal non-commercial use only. The Journal of Rheumatology Copyright (C) 2019. All rights reserved 


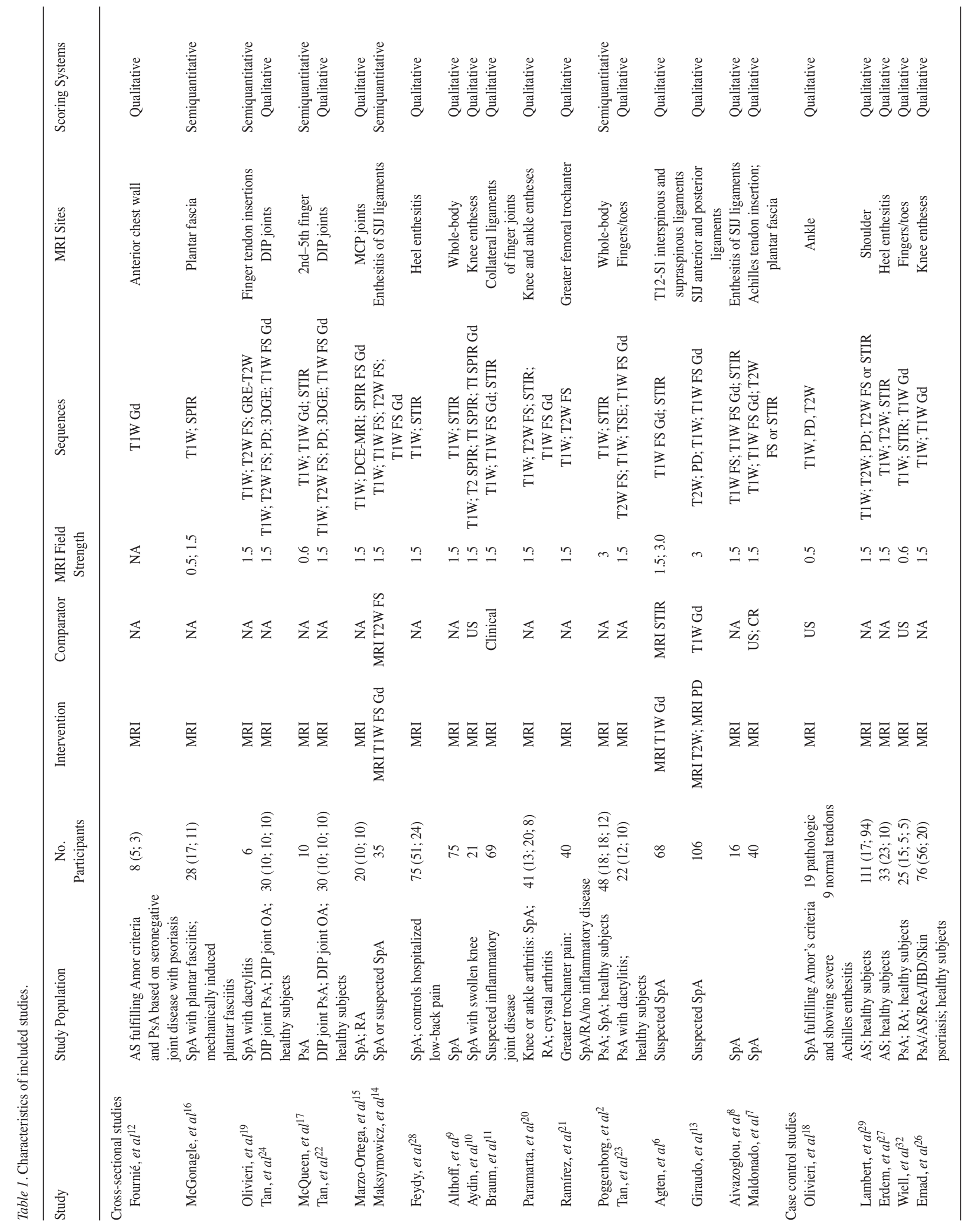

Personal non-commercial use only. The Journal of Rheumatology Copyright @ 2019 . All rights reserved. 


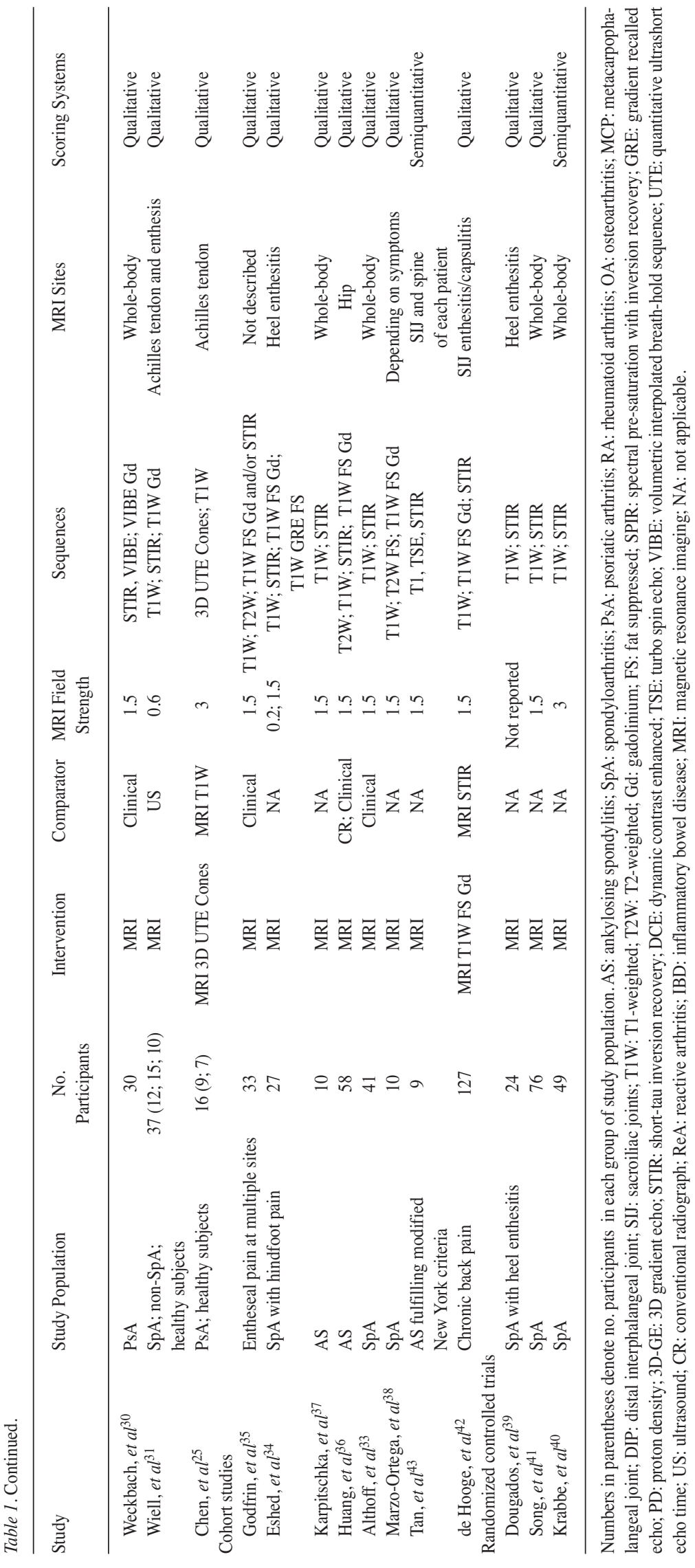

Personal non-commercial use only. The Journal of Rheumatology Copyright $\odot ~ 2019$. All rights reserved. 
Table 2. Psychometric properties and quality scores of selected studies $(\mathrm{n}=38)$.

\begin{tabular}{|c|c|c|c|c|c|c|c|}
\hline Study & Face Validity* & $\begin{array}{c}\text { Content } \\
\text { Validity* }\end{array}$ & $\begin{array}{l}\text { Construct } \\
\text { Validity* }\end{array}$ & $\begin{array}{l}\text { Criterion } \\
\text { Validity* }\end{array}$ & Reliability* & Responsiveness* & $\begin{array}{l}\text { Quality } \\
\text { Scoring }\end{array}$ \\
\hline \multicolumn{8}{|l|}{ Cross-sectional studies } \\
\hline Olivieri, et al ${ }^{19}$ & YES & NO & NO & NO & NO & NO & 7 \\
\hline Tan, et $a l^{24}$ & YES & NO & $\mathrm{NO}$ & NO & YES & $\mathrm{NO}$ & 7 \\
\hline McQueen, et al ${ }^{17}$ & YES & YES & NO & $\mathrm{NO}$ & YES & NO & 8 \\
\hline Maksymowicz, et al ${ }^{14}$ & NO & NO & NO & $\mathrm{NO}$ & NO & NO & 6 \\
\hline Althoff, et $a l^{9}$ & YES & YES & NO & NO & YES & NO & 7 \\
\hline Aydin, et $a l^{10}$ & YES & YES & YES & NO & YES & NO & 8 \\
\hline Braum, et al ${ }^{11}$ & YES & YES & YES & $\mathrm{NO}$ & NO & NO & 7 \\
\hline Ramírez, et al ${ }^{21}$ & YES & NO & NO & NO & NO & NO & 8 \\
\hline Paramarta, et al ${ }^{20}$ & YES & YES & NO & NO & YES & NO & 7 \\
\hline Maldonado, et $a l^{7}$ & YES & YES & YES & NO & YES & NO & 7 \\
\hline Aivazoglou, $e t a l^{8}$ & YES & NO & YES & $\mathrm{NO}$ & NO & $\mathrm{NO}$ & 7 \\
\hline \multicolumn{8}{|l|}{ Case control studies } \\
\hline Olivieri, et al ${ }^{18}$ & YES & YES & YES & $\mathrm{NO}$ & NO & $\mathrm{NO}$ & 6 \\
\hline Lambert, et a ${ }^{29}$ & YES & YES & NO & $\mathrm{NO}$ & YES & NO & 6 \\
\hline Erdem, et $a l^{27}$ & YES & YES & NO & $\mathrm{NO}$ & YES & $\mathrm{NO}$ & 5 \\
\hline Wiell, et $a l^{32}$ & YES & NO & NO & NO & NO & NO & 8 \\
\hline Emad, et $a l^{26}$ & YES & NO & NO & NO & YES & NO & 6 \\
\hline Weckbach, et al ${ }^{30}$ & YES & NO & YES & $\mathrm{NO}$ & YES & $\mathrm{NO}$ & 7 \\
\hline Feydy, et al ${ }^{28}$ & YES & NO & NO & NO & YES & NO & 8 \\
\hline Wiell, et $a l^{31}$ & YES & YES & YES & NO & YES & NO & 9 \\
\hline Chen, et $a l^{25}$ & YES & YES & YES & $\mathrm{NO}$ & NO & NO & 6 \\
\hline de Hooge, et $a l^{42}$ & YES & NO & YES & NO & NO & YES & 9 \\
\hline \multicolumn{8}{|c|}{ Randomized controlled trials } \\
\hline Dougados, et $a l^{39}$ & NO & NO & NO & $\mathrm{NO}$ & NO & NO & 7 \\
\hline Song, et $a l^{41}$ & YES & NO & NO & NO & YES & YES & 9 \\
\hline Krabbe, et $a l^{40}$ & YES & YES & NO & $\mathrm{NO}$ & YES & YES & 11 \\
\hline
\end{tabular}

* Face validity was defined as expert opinion on the credibility of scoring system used in each article to measure enthesitis. Content validity estimated the reliability of the scoring system used in each study to measure the full spectrum of outcome - inflammatory and structural changes. Construct validity was achieved when MRI evaluation of enthesitis correlated with the following concepts of enthesitis: (1) clinical assessment of enthesitis using a validated enthesitis score (e.g., MASES), (2) ultrasound or radiographic assessment of enthesitis sites, and/or (3) comparison of different sequences of MRI in assessing enthesitis. Criterion validity was achieved when MRI evaluation of enthesitis correlated with a gold standard (e.g., histology). Reliability was defined in studies mentioning inter-rater reliability measures of scoring consistency between and within MRI readers, e.g., inter/intraclass correlation coefficients or $x$ statistics. Responsiveness was achieved in studies documenting statistically significant changes in relation to treatment introduction or change. MRI: magnetic resonance imaging; MASES: Maastricht Ankylosing Spondylitis Enthesitis Score.

methods of evaluating enthesitis using MRI in patients with SpA and PsA, and identified notable limitations regarding standardization of MRI enthesitis definitions across studies and validity of available semiquantitative scores as outcome measures. The findings suggest there is no currently available reliable and validated MRI scoring system for enthesitis.
Many studies have included different definitions of MRI lesions suggestive of enthesitis, hindering direct comparison of the available methods. A fifth of the selected studies described a semiquantitative scoring system, albeit without standardization and internal validity, because all were developed based on expert opinion. 


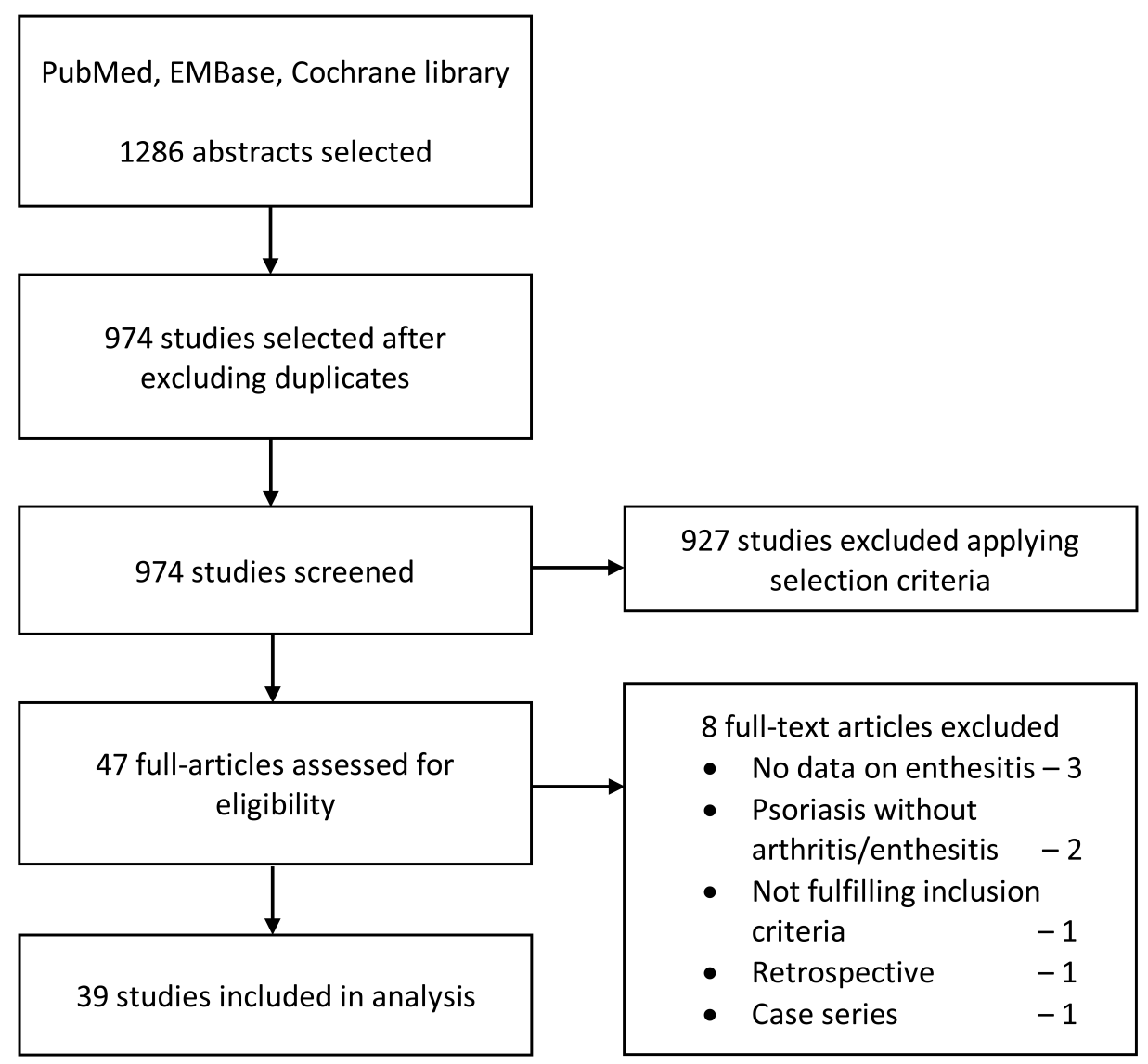

Figure 1. Flow diagram of article selection (PRISMA: Preferred Reporting Items for Systematic reviews and Meta-Analyses).

Poor content validity of reported scoring methods was another limitation of the literature. Most studies have focused on assessing inflammatory aspects of enthesitis and not the structural variables, which denote chronic, irreversible changes. MRI inflammatory lesions are amenable to change and responsive to therapy. Wide variation in the entheseal sites to be assessed adds to the challenge in standardization. Lack of a standardized definition to define the borders of enthesitis makes it difficult to differentiate it from other inflammatory variables, such as synovitis and tenosynovitis, thus increasing the variability of scores in each study.

Construct validity was evaluated in relation to US and clinical examination. Most of the studies showed poor correlation between MRI and US. This again emphasizes the lack of standardized definitions of MRI enthesitis lesions. Limited information exists regarding criterion validity because only 1 study compared MRI with histology. Lack of significant responsiveness of available qualitative and semiquantitative MRI enthesitis scores suggests limited utility as outcome measures in clinical trials.

The above-mentioned limitations and the lack of validated, generally accepted MRI enthesitis assessment systems warrant the development of a reliable and feasible
MRI enthesitis scoring system to increase the utility of MRI as an outcome measure in SpA and PsA clinical trials.

\section{ONLINE SUPPLEMENT}

Supplementary material accompanies the online version of this article.

\section{REFERENCES}

1. Eshed I, Bollow M, McGonagle DG, Tan AL, Althoff CE, Asbach P, et al. MRI of enthesitis of the appendicular skeleton in sponydloarthritis. Ann Rheum Dis 2007;66:1553-9.

2. Poggenborg RP, Eshed I, Østergaard M, Sørensen IJ, Møller JM, Madsen OR, et al. Enthesitis in patients with psoriatic arthritis, axial spondyloarthritis and healthy subjects assessed by 'head-to-toe' whole-body MRI and clinical examination. Ann Rheum Dis 2015;74:823-9

3. Boers M, Kirwan JR, Tugwell P, Beaton D, Bingham CO III, Conaghan PG, et al. The OMERACT Handbook. [Internet. Accessed May 17, 2017.] Available from: https://omeract.org/resources

4. Boers M, Kirwan JR, Wells G, Beaton D, Gossec L, d'Agostino MA, et al. Developing core outcome measurement sets for clinical trials: OMERACT filter 2.0. J Clin Epidemiol 2014;67:745-53.

5. Downs SH, Black N. The feasibility of creating a checklist for the assessment of the methodological quality both of randomised and non-randomised studies of health care interventions. J Epidemiol Community Health 1998;52:377-84. 
6. Agten CA, Zubler V, Rosskopf AB, Weiss B, Pfirrmann CW. Enthesitis of lumbar spinal ligaments in clinically suspected spondyloarthritis: value of gadolinium-enhanced MR images in comparison to STIR. Skeletal Radiol 2016;45:187-95.

7. Aguila Maldonado R, Ruta S, Valuntas ML, Garcia M. Ultrasonography assessment of heel entheses in patients with spondyloarthritis: a comparative study with magnetic resonance imaging and conventional radiography. Clin Rheumatol 2017;36:1811-17.

8. Aivazoglou LU, Zotti OR, Pinheiro MM, Junior MRC, Puchnick A, Fernandes ADRC, et al. Topographic MRI evaluation of the sacroiliac joints in patients with axial spondyloarthritis. Rev Bras Reumatol Engl Ed 2017;57:378-84.

9. Althoff CE, Seiper J, Song IH, Haibel H, Weiß A, Diekhoff T, et al. Active inflammation and structural change in early active axial spondyloarthritis as detected by whole-body MRI. Ann Rheum Dis 2013;72:967-73.

10. Aydin SZ, Tan AL, Hodsgon R, Grainger A, Emery P, Wakefield RJ, et al. Comparison of ultrasonography and magnetic resonance imaging for the assessment of clinically defined knee enthesitis in spondyloarthritis. Clin Exp Rheumatol 2013;31:933-6.

11. Braum LS, McGonagle D, Bruns A, Philipp S, Hermann S, Aupperle K, et al. Characterisation of hand small joints arthropathy using high-resolution MRI-limited discrimination between osteoarthritis and psoriatic arthritis. Eur Radiol 2013;23:1686-93.

12. Fournié B, Boutes A, Dromer C, Sixou L, Le Guennec P, Granel J, et al. Prospective study of anterior chest wall involvement in ankylosing spondylitis and psoriatic arthritis. Rev Rhum Engl Ed 1997;64:22-5.

13. Giraudo C, Magnaldi S, Weber M, Puchner A, Platzgummer H, Kainberger F, et al. Optimizing the MRI protocol of the sacroiliac joints in spondyloarthritis: which para-axial sequence should be used? Eur Radiol 2016;26:122-9.

14. Maksymowicz H, Kowalewski K, Lubkowska K, Zołud W, Sąsiadek M. Diagnostic value of gadolinium-enhanced MR imaging of active sacroiliitis in seronegative spondyloarthropathy. Pol J Radiol 2010;75:58-65.

15. Marzo-Ortega H, Tanner SF, Rhodes LA, Tan AL, Conaghan PG, Hensor EM, et al. Magnetic resonance imaging in the assessment of metacarpophalangeal joint disease in early psoriatic and rheumatoid arthritis. Scand J Rheumatol 2009;38:79-83.

16. McGonagle D, Marzo-Ortega H, O'Connor P, Gibbon W, Pease C, Reece $\mathrm{R}$, et al. The role of biomechanical factors and HLA-B27 in magnetic resonance imaging-determined bone changes in plantar fascia enthesopathy. Arthritis Rheum 2002;46:489-93.

17. McQueen F, Lassere M, Bird P, Haavardsholm EA, Peterfy C, Conaghan PG, et al. Developing a magnetic resonance imaging scoring system for peripheral psoriatic arthritis. J Rheumatol 2007;34:859-61.

18. Olivieri I, Barozzi L, Padula A, De Matteis M, Pierro A, Cantini F, et al. Retrocalcaneal bursitis in spondyloarthropathy: assessment by ultrasonography and magnetic resonance imaging. J Rheumatol 1998;25:1352-7.

19. Olivieri I, Salvarani C, Cantini F, Scarano E, Padula A, Niccoli L, et al. Fast spin echo-T2-weighted sequences with fat saturation in dactylitis of spondylarthritis. No evidence of entheseal involvement of the flexor digitorum tendons. Arthritis Rheum 2002;46:2964-7.

20. Paramarta JE, van der Leij C, Gofita I, Yeremenko N, van de Sande MG, de Hair MJ, et al. Peripheral joint inflammation in early onset spondyloarthritis is not specifically related to enthesitis. Ann Rheum Dis 2014;73:735-40.

21. Ramírez J, Pomés I, Sobrino-Guijarro B, Pomés J, Sanmartí R, Cañete JD. Ultrasound evaluation of greater trochanter pain syndrome in patients with spondyloarthritis: are there any specific features? Rheumatol Int 2014;34:947-52.
22. Tan AL, Benjamin M, Toumi H, Grainger AJ, Tanner SF, Emery P, et al. The relationship between the extensor tendon enthesis and the nail in distal interphalangeal joint disease in psoriatic arthritis - a high-resolution MRI and histological study. Rheumatology 2007;46:253-6.

23. Tan AL, Fukuba E, Halliday NA, Tanner SF, Emery P, McGonagle D. High-resolution MRI assessment of dactylitis in psoriatic arthritis shows flexor tendon pulley and sheath-related enthesitis. Ann Rheum Dis 2015;74:185-9.

24. Tan AL, Grainger AJ, Tanner SF, Emery P, McGonagle D. A high-resolution magnetic resonance imaging study of distal interphalangeal joint arthropathy in psoriatic arthritis and osteoarthritis: are they the same? Arthritis Rheum 2006;54:1328-33.

25. Chen B, Zhao Y, Cheng X, Ma Y, Chang EY, Kavanaugh A, et al. Three-dimensional ultrashort echo time cones (3D UTE-Cones) magnetic resonance imaging of entheses and tendons. Magn Reson Imaging 2018;49:4-9.

26. Emad Y, Ragab Y, Bassyouni I, Moawayh O, Fawzy M, Saad A, et al. Enthesitis and related changes in the knees in seronegative spondyloarthropathies and skin psoriasis: magnetic resonance imaging case-control study. J Rheumatol 2010;37:1709-17.

27. Erdem CZ, Sarikaya S, Erdem LO, Ozdolap S, Gundogdu S. MR imaging features of foot involvement in ankylosing spondylitis. Eur J Radiol 2005;53:110-9.

28. Feydy A, Lavie-Brion MC, Gossec L, Lavie F, Guerini H, Nguyen $\mathrm{C}$, et al. Comparative study of MRI and power Doppler ultrasonography of the heel in patients with spondyloarthritis with and without heel pain and in controls. Ann Rheum Dis 2012; 71:498-503.

29. Lambert RG, Dhillon SS, Jhangri GS, Sacks J, Sacks H, Wong B, et al. High prevalence of symptomatic enthesopathy of the shoulder in ankylosing spondylitis: deltoid origin involvement constitutes a hallmark of disease. Arthritis Rheum 2004;51:681-90.

30. Weckbach S, Schewe S, Michaely HF, Steffinger D, Reiser MF, Glaser C. Whole-body MR imaging in psoriatic arthritis: additional value for therapeutic decision making. Eur J Radiol 2011;77:149-55.

31. Wiell C, Szkudlarek M, Hasselquist M, Møller JM, Nørregaard J, Terslev L, et al. Power Doppler ultrasonography of painful Achilles tendons and entheses in patients with and without spondyloarthropathy: a comparison with clinical examination and contrast-enhanced MRI. Clin Rheumatol 2013;32:301-8.

32. Wiell C, Szkudlarek M, Hasselquist M, Møller JM, Vestergaard A, Nørregaard J, et al. Ultrasonography, magnetic resonance imaging, radiography, and clinical assessment of inflammatory and destructive changes in fingers and toes of patients with psoriatic arthritis. Arthritis Res Ther 2007;9:R119.

33. Althoff CE, Sieper J, Song IH, Weiß A, Deikhoff T, Haibel H, et al. Comparison of clinical examination versus whole-body magnetic resonance imaging of enthesitis in patients with early axial spondyloarthritis during 3 years of continuous etanercept. J Rheumatol 2016;43:618-24.

34. Eshed I, Althoff CE, Feist E, Minden K, Schink T, Hamm B, et al. Magnetic resonance imaging of hindfoot involvement in patients with spondyloarthritides: comparison of low-field and high-field strength units. Eur J Radiol 2008;65:140-7.

35. Godfrin B, Zabraniecki L, Lamboley V, Bertrand-Latour F, Sans N, Fournie B. Spondyloarthropathy with entheseal pain. A prospective study in 33 patients. Joint Bone Spine 2004;71:557-62.

36. Huang ZG, Zhang XZ, Hong W, Wang GC, Zhou HQ, Lu X, et al. The application of MR imaging in the detection of hip involvement in patients with ankylosing spondylitis. Eur J Radiol 2013; 82:1487-93

37. Karpitschka M, Godau-Kellner P, Kellner H, Horng A, Theisen D, Glaser C, et al. Assessment of therapeutic response in ankylosing spondylitis patients undergoing anti-tumour necrosis factor therapy

Personal non-commercial use only. The Journal of Rheumatology Copyright @ 2019 . All rights reserved. 
by whole-body magnetic resonance imaging. Eur Radiol 2013;23:1773-84.

38. Marzo-Ortega H, McGonagle D, O'Connor P, Emery P. Efficacy of etanercept in the treatment of the entheseal pathology in resistant spondylarthropathy: a clinical and magnetic resonance imaging study. Arthritis Rheum 2001;44:2112-7.

39. Dougados M, Combe B, Braun J, Landewé R, Sibilia J, Cantagrel A, et al. A randomised, multicentre, double-blind, placebo-controlled trial of etanercept in adults with refractory heel enthesitis in spondyloarthritis: the HEEL trial. Ann Rheum Dis 2010;69:1430-5.

40. Krabbe S, Østergaard M, Eshsed I, Sørensen IJ, Jensen B, Møller $\mathrm{JM}$, et al. Whole-body magnetic resonance imaging in axial spondyloarthritis: reduction of sacroiliac, spinal, and entheseal inflammation in a placebo-controlled trial of adalimumab. J Rheumatol 2018;45:621-9.

41. Song IH, Hermann K, Haibel H, Althoff CE, Listing J, Burmester G, et al. Effects of etanercept versus sulfasalazine in early axial spondyloarthritis on active inflammatory lesions as detected by whole-body MRI (ESTHER): a 48-week randomised controlled trial. Ann Rheum Dis 2011;70:590-6.

42. de Hooge M, van den Berg R, Navarro-Compan V, van Gaalen F, van der Heijde D, Huizinga T, et al. Magnetic resonance imaging of the sacroiliac joints in the early detection of spondyloarthritis: no added value of gadolinium compared with short tau inversion recovery sequence. Rheumatology 2013;52:1220-4.

43. Tan AL, Marzo-Ortega H, O'Connor P, Fraser A, Emery P, McGonagle D. Efficacy of anakinra in active ankylosing spondylitis: a clinical and magnetic resonance imaging study. Ann Rheum Dis 2004;63:1041-5.

44. Orbai AM, de Wit M, Mease PJ, Callis Duffin K, Elmamoun M, Tillett W, et al. Updating the psoriatic arthritis (PsA) core domain set: a report from the PsA workshop at OMERACT 2016. J Rheumatol 2017;44:1522-8. 